\title{
Social reinstatement and open-field testing in chickens
}

\author{
SUSAN D. SUAREZ and GORDON G. GALLUP, JR. \\ State University of New York, Albany, New York
}

\begin{abstract}
Based on a model which holds that open-field behavior represents a combination of predator evasion tactics and attempts to reinstate contact with conspecifics, five experiments were conducted with chickens to assess the effects on them of social separation in response to being placed in a novel enclosure. As a means of independently demonstrating reinstatement tendencies, it was shown that birds would run faster down a straight alley if the goalbox contained one or more conspecifics than if it was empty or contained a guinea pig. For birds tested in pairs, the effects were different, depending on whether they had been reared in pairs or in larger groups. On the other hand, although chicks froze and remained silent longer in pairs, they seemed to be relatively insensitive to whether the pair member was a cagemate or a stranger. Finally, as predicted, reinstatement tendencies diminished and predator evasion tactics predominated with increasing age.
\end{abstract}

Since its introduction by Hall (1934) almost 50 years ago, the open field, defined as a novel enclosure that is larger than the home cage, has been used widely as a behavioral test on a variety of species. Practically all reactions (e.g., ambulation, rearing, vocalization, defecation) have at one time or another been interpreted as measures of "emotionality," a concept which is rarely operationalized but is considered to be "an entity underlying the nonspecific affective components of behavior" (Walsh \& Cummins, 1976, p. 500). Due to inconsistent results that often fail to replicate among species and testing situations, the usefulness of an emotionality construct has repeatedly been questioned (see Archer, 1973, and Walsh \& Cummins, 1976, for reviews). We have proposed an alternative model of open-field behavior (Gallup \& Suarez, 1980) which is based on two important, but previously unacknowledged, features of the testing situation. The first is that most animals are subjected to sudden social separation from familiar and/or imprinted conspecifics by virtue of being removed from the home cage and tested in isolation. The second aspect relates to the possibility that animals are typically, but unintentionally, exposed to a simulated predatory encounter as a consequence of contact and restraint by a human being during removal from the home cage and placement in the open field. Openfield behavior might be viewed as an interaction or compromise between the opposing tendencies to

We thank E. Riley and B. Svare for helpful comments on an earlier draft of this paper. This work was partially supported by a National Science Foundation predoctoral fellowship held by the first author. Reprint requests should be directed to G. G. Gallup, Jr., Department of Psychology, SUNY, Albany, New York 12222. reinstate social contact and evade further predatory activity.

Under natural conditions, the young of many precocial avian species emit distress calls and move about when separated from the mother or broodmates. These behaviors are thought to function as a means of facilitating maternal detection and reestablishing social contact (Brückner, 1933; Collias, 1952; Guiton, 1959; Kruijt, 1964; Sluckin, 1965). Under the threat of predation, diametrically opposite behaviors occur. Vocalization and movement normally cease upon initial detection of a predator (e.g., Andrew, 1956; Armstrong, 1955; Stoddard, 1936; Stokes, 1967). Since many predators rely heavily on auditory (Busnel, 1963) and moving visual cues from prey in order to begin or continue with an attack (Askew, Musimeci, Sloane, \& Stephan, 1970; Drummond, 1979; Herzog \& Burghardt, 1974; Kaufman, 1974; MacDonald, 1973), it is believed that freezing (i.e., cessation of movement) and silence function to preclude detection or abort further pursuit (Cott, 1940; Curio, 1976; White \& Weeden, 1966). Several studies designed to vary threat of predation have produced effects on vocalization and movement by birds and rodents in an open field that are consistent with this model (see Gallup \& Suarez, 1980; Suarez \& Gallup, 1980, 1981a, 1981b, 1982a, 1982b).

Little attention has been paid to the other aspect of our model, social reinstatement. In an attempt to alter social reestablishment tendencies, animals have been housed either in groups or in social isolation prior to testing. According to our hypothesis, the behavior of group-reared subjects should be dictated by the opposing tendencies of attempting to reinstate contact with conspecifics and evad- 
ing predation, while that of isolate-housed animals should be aimed primarily at minimizing detectability, because isolation diminishes attempts to reunite with conspecifics (see Baron \& Kish, 1960; Collias, 1950). In accord with this prediction, isolatehoused chicks and ducks were silent and froze longer in the open field than their group-housed counterparts (Gallup \& Suarez, 1980; Suarez \& Gallup, 1980). Similar results have been reported for rodents (Ader, 1965; Berg, Shanin, \& Hull, 1975; Korn \& Moyer, 1968; Thiessen, 1963). Another method of varying social motivation is to test animals in an open field individually or in pairs. The presence of a familiar animal should reduce the motivation to reinstate social contact, making predator evasion in the form of freezing and silence the predominant initial response to the open field in pair-tested animals. This prediction has been borne out with rats, mice, ducks, and chickens (Gallup \& Suarez, 1980; Gervais, 1976; Goodrick, 1965; Randall \& Campbell, 1976; Suarez \& Gallup, 1980, 1981a; Syme \& Syme, 1974).

The experiments reported here were designed to explore more fully the role of social reinstatement motivation in open-field testing in chickens.

\section{EXPERIMENT 1}

Given that the same preconditions for testing (i.e., human contact and social separation) are typically encountered in a variety of commonly used pieces of behavioral testing equipment, the first experiment attempted to independently assess the premise that brief separation from familiar companions motivates an animal to reinstate social contact. Group-reared chicks were individually tested in a runway with four, one, or no other birds present in a holding compartment at the other end. If separation motivates social reinstatement, then one would expect approach latency to be a function of number of conspecifics present. For instance, Gaioni, Hoffman, Klein, and DePaulo (1977) found that the time ducklings spent distress calling was a monotonic function of the magnitude of reduction in group size. It was predicted, therefore, that subjects tested with four chicks in the holding compartment should take less time to traverse the runway than those tested with one bird present, and that the latter subjects, in turn, should run faster than those for which no other birds were present.

\section{Method}

Subjects. The subjects were $3031 \frac{1}{2}$-week-old straight-run Production Red chickens (Gallus gallus) obtained from a commercial supplier (Welp) at 1 day of age. All chicks were housed as a group in a thermostatically controlled brooder under a 14-h photoperiod with a continuous supply of food and water. The brooder rack was shielded by an opaque barrier in order to limit the amount of incidental human exposure the subjects received.
Apparatus. Testing was conducted in a fiberboard runway that measured $35 \mathrm{~cm}$ wide $\times 246 \mathrm{~cm}$ long $\times 46 \mathrm{~cm}$ high. A holding compartment at one end of the runway was built by positioning a clear sheet of Plexiglas $30 \mathrm{~cm}$ from the end wall. One strip of black tape placed on the floor across the width of the runway at a distance of $15 \mathrm{~cm}$ from the Plexiglas shield served as the finish line, and another piece $15 \mathrm{~cm}$ from the opposite end was used as the start line. The runway was covered with wire mesh panels.

Procedure. Ten chicks were assigned randomly to each of three groups and tested under normal room illumination during the midportion of the light period. All subjects were removed individually from the brooder and transported to the runway in a cardboard box. Each chick was placed at the start line and timed on a stopwatch to the nearest second (by an experimenter who was hidden from view by a plywood barrier) for latency to cross the finish line with both feet. Subjects in one group were tested with four other group-housed birds present in the holding compartment throughout the test; chicks in the second group were tested with one other bird present; and subjects in the final group were tested in the absence of any birds in the holding compartment. Testing order was determined by randomized block. The stimulus birds were a sample of 20 chicks from the same hatch as the subjects and were randomly and repeatedly assigned to conditions during testing. Any chicks not crossing the finish line in $20 \mathrm{~min}$ were assigned a running latency of $1,200 \mathrm{sec}$. Defecations were removed and the floor was wiped clean with disinfectant after each test.

\section{Results}

Figure 1 shows the mean latencies to cross the finish line for the different groups. An analysis of variance indicated that the overall effect was significant $[F(2,27)=7.27, p<.005]$. Orthogonal comparisons also showed that chicks tested without any birds present in the holding compartment took significantly longer to cross the finish line than the groups in which one or four other birds were present combined $[F(1,27)=9.90, p<.005]$. Chicks tested with four birds in the holding compartment had shorter latencies to cross the finish line than did those tested with only one other bird present $[F(1,27)=4.64, p<.05]$. Thus, it appears that sub-

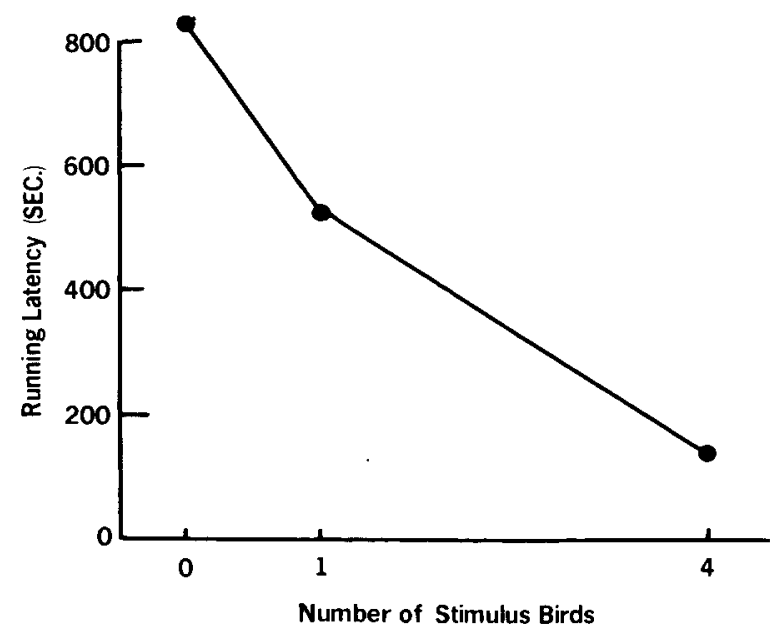

Figure 1. Mean runway latencies in chickens produced by varying number of goal animals. 
jects tested individually are motivated by social reinstatement and that running latencies are a function of the number of conspecifics the animal has the opportunity to reunite with.

\section{EXPERIMENT 2}

One might argue that chicks that are subjected to acute social separation may traverse a runway simply to investigate any object at the other end rather than to reunite with conspecifics. In order to assess this possibility, chicks in the second experiment were tested alone or with a peer or a guinea pig as the goal animal.

\section{Method}

Subjects. The subjects were $2721 / 2$-week-old straight-run Production Red chickens obtained and maintained as in the first experiment.

Apparatus and Procedure. Testing was conducted in the same runway used in the previous experiment. To reduce variability in running latencies, the finish line was positioned $30.5 \mathrm{~cm}$ from the holding compartment and the start line was $30.5 \mathrm{~cm}$ from the opposite end. The same illumination conditions were in effect, and testing occurred during the same interval of the photoperiod. Nine chicks were assigned randomly to each of three groups. An adult female pigmented guinea pig was present in the holding compartment for one group, and a same-aged grouphoused chick was contained in the holding compartment for the second group. The holding compartment was empty for the remaining group. Methods of observation and timing of finish latencies were the same as in the first experiment, with the exception that an 1,800-sec ceiling was employed. Defecations were removed, and the floor was cleaned after each test.

\section{Results}

The data are depicted in Figure 2. An analysis of variance showed a significant effect of goalbox condition $[F(2,24)=4.56, p<.025]$. An orthogonal comparison showed that chicks tested with another chick in the goalbox crossed the finish line signif-

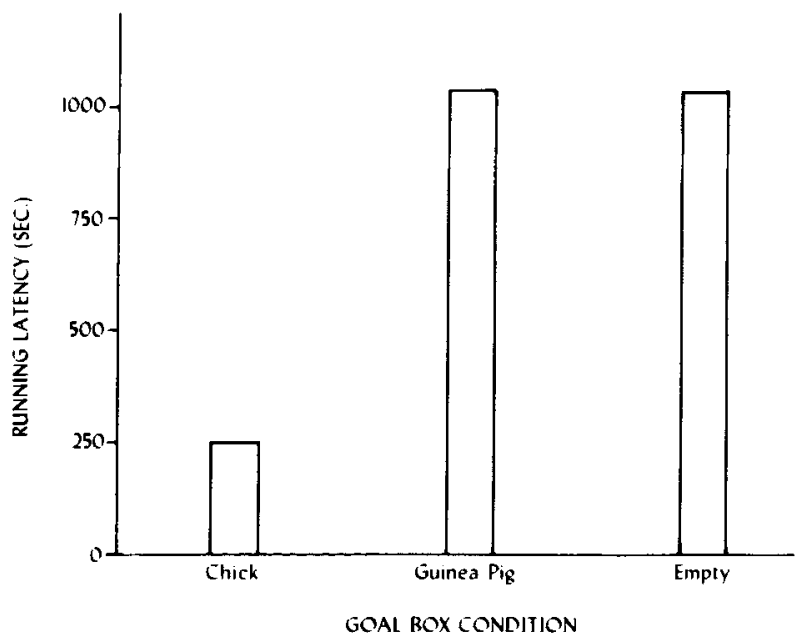

Figure 2. Mean runway latencies in chickens as a function of species of goal animal. icantly sooner than did the combined groups in which the goalbox was empty or contained a guinea pig $[F(1,24)=9.12, p<.01]$. The latter two groups did not differ from each other. Thus, it appears that species-specific social reunion, rather than curiosity and/or object investigation, is the primary motivation underlying runway performance.

\section{EXPERIMENT 3}

After having established with the first two experiments that separation from conspecifics motivates social reunion, the third experiment assessed the effects produced on open-field behavior by groupsize reductions. Chicks were housed in groups of 10,6 , or 2 before being tested in pairs in the open field. It was predicted that birds both raised and tested in pairs should remain silent and inactive longer because they experience no social separation during testing. Since birds raised in groups of 10 are separated from the greatest number of conspecifics during testing, they should be the most motivated to reinstate social contact, thus showing the shortest distress call and ambulation latencies.

\section{Method}

Subjects. The subjects were 60 straight-run Production Red chickens obtained and cared for as described previously.

Apparatus. Testing was conducted in a plywood open-field box that measured $88.9 \times 88.9 \times 40.6 \mathrm{~cm}$ high and was painted flat black with white lines dividing the floor into a grid of 25 squares (each $17.5 \times 17.5 \mathrm{~cm}$ ). Open-field behavior was remotely monitored on a closed-circuit television system that consisted of a Panasonic TV camera (WV-341P) and microphone, a Panasonic monitor (TR-195V), and an International Video Corp. recorder (IVC-700).

Procedure. At 2 weeks of age, the chicks were removed from the original group brooder and, in groups of 2,6 , or 10 , placed in brooders that were divided in half by plywood partitions. There were 10 such compartments for each housing condition. Since chickens can recognize each other as individuals (Guhl \& Ortman, 1953), the special housing conditions remained in effect for 10 days in order to allow brooder mates to become familiar with each other. On the test day, a single pair, selected randomly from each compartment, was given an open-field test. Both chicks were carried to the testing room in a cardboard box and placed together in the central square of the open field. After lowering the box lid, the experimenter left the room. The illumination and photoperiod conditions for testing were the same as those in the preceding experiments. Activity was monitored via closed-circuit television in an adjacent room. Latencies to distress call and ambulate from the center square with both feet were timed on stopwatches to the nearest second from the moment subjects were placed in the open field. Latencies were scored when either member of a pair first distress-called and/or ambulated. Thus, the behavior of a pair was treated as a single unit of measurement. The subjects were allowed to remain in the open field for a maximum of $\mathbf{4 0} \mathrm{min}$, after which scores of $2,400 \mathrm{sec}$ were assigned to the appropriate latency measure.

\section{Results}

The data are shown in Figure 3. A $\log (x+1)$ transformation was performed on the distress call latency scores to eliminate heterogeneity of vari- 


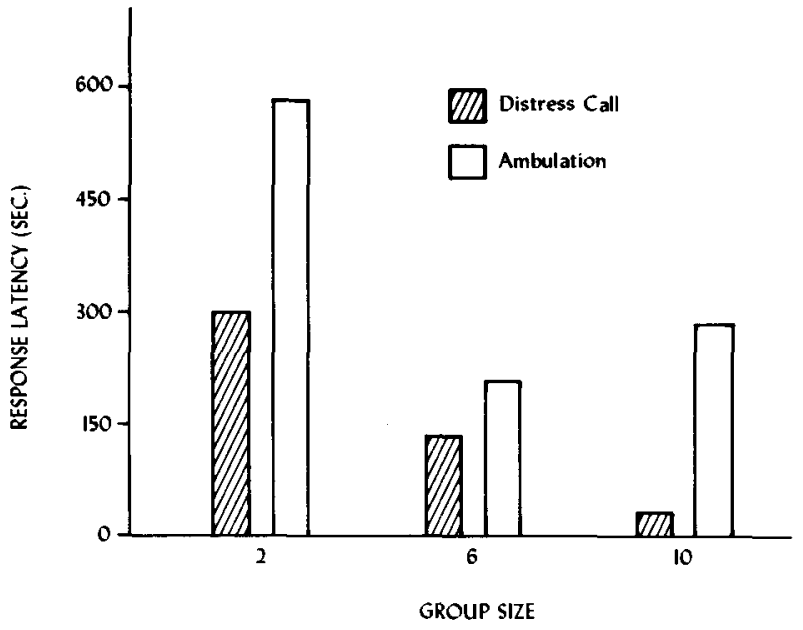

Figure 3. Open-field behavior of chick pairs as a function of prior housing density.

ance. A subsequent analysis of variance showed that the overall difference between groups did not reach significance $[F(2,27)=2.87, p<.10]$. A trend analysis showed the linear component to be significant $[F(1,27)=5.40, p<.05]$, with birds showing progressively shorter latencies to begin distresscalling the larger the group of chicks they had been separated from during testing had been. The quadratic component was not significant.

An analysis of variance of ambulation latencies yielded no significant difference among groups, and a trend analysis revealed that neither the linear nor the quadratic component was statistically significant.

Therefore, only distress-call latency appeared to be influenced by whether the testing condition encompassed total or partial social reinstatement.

\section{EXPERIMENT 4}

In theory, who a subject had been separated from should make a difference. For instance, when birds are tested in the open field in pairs, one might expect the familiarity of pair members to affect the occurrence of social reinstatement behaviors. In order to test this prediction, chicks in Experiment 4 were housed in pairs and tested in the open field alone, with a cagemate, or with a pair-housed stranger.

\section{Method}

Subjects. Eighty straight-run Production Red chickens served as subjects. Methods of procurement and care were the same as in the preceding studies.

Apparatus and Procedure. The same open field and video monitoring equipment were used as described previously. At $2 \frac{1}{2}$ weeks of age, all chicks were removed from the original group brooder and housed in pairs as described for the third experiment. Ten days later, they were tested once in the open field alone, with the cagemate, or with a pair-housed stranger to which they had not been exposed previously. The chicks were assigned randomly to the three groups such that there were 16 data points per dependent variable per group. Distress-call and ambulation latencies were recorded for those tested individually or in pairs according to the method described earlier.

\section{Results}

Figure 4 depicts the results. An analysis of variance of distress-call scores failed to show an overall significant difference between groups $[\mathrm{F}(2,45)=$ $3.02, p<.10$ ]. However, an orthogonal comparison showed that chicks tested alone had shorter latencies to begin distress calling than did the pairtested groups combined $[F(1,45)=5.36, p<.05]$. Birds tested with the cagemate did not differ from those in which testing was conducted in the presence of a stranger. No birds in the alone condition, two in the stranger condition, and two tested with the cagemate reached the $2,400-\mathrm{sec}$ ceiling. In order to mitigate the possibility that the failure to find a difference between the cagemate and stranger conditions might have been due to the imposition of a ceiling, a chi-square test was conducted on the frequency of birds' reaching the ceiling. The result was not significant.

An analysis of variance of ambulation latencies showed a significant difference between groups $[F(2,45)=5.62, p<.01]$. An orthogonal comparison of chicks tested individually with the cagemate and stranger groups combined was also significant $[F(1,45)=8.38, p<.011$. The cagemate and stranger groups were not different from each other. However, a chi-square test performed on the frequency of subjects reaching the imposed ceiling (two in the stranger condition and six in the cagemate condition) was statistically significant $\left[\chi_{2}(1)=12.51, p<.001\right]$. Thus, the failure to find a difference in ambulation latency between the stranger and cagemate groups may have been an artifact of the use of an arbitrary ceiling.

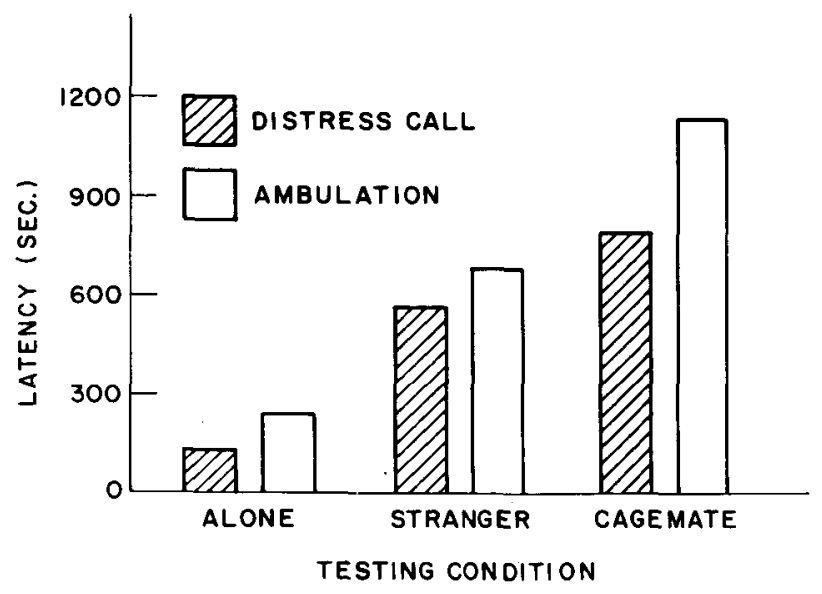

Figure 4. The effects of prior familiarity on mean distress call and ambulation latencies in chickens. 


\section{EXPERIMENT 5}

Reliance on the mother for warmth, nutrition, protection from predators, and various other resources that contribute to survival generally tends to decrease with age in many species. For precocial birds raised artificially in groups without the mother, one would expect that attachment to the social group might follow a similar developmental time course. Consequently, it would follow, from our model, that social reinstatement tendencies in chickens should be inversely proportional to age, making predator evasion behaviors (i.e., freezing, silence) in the open field more likely with increasing maturity. Accordingly, in the fifth experiment group-reared chicks were individually tested in the open field at 7,14 , 21,30 , or 40 days of age.

\section{Method}

Subjects. The subjects were 55 straight-run Production Red chickens obtained as described earlier. Upon arrival, they were housed in five separate brooders with other same-aged chicks not used in the present study, to provide groups of 20 chicks per brooder. Method of maintenance was the same as in the previous studies.

Apparatus and Procedure. The open field and closed-circuit television system were the same as those in the third and fourth experiments. Eleven randomly selected chicks were assigned to each of five groups and individually tested in the open field at $7,14,21,30$, or 40 days of age. One brooder of chicks was used for each age. Open-field testing was conducted in the absence of an experimenter and with the lid of the field closed, but under the same illumination and photoperiod conditions as employed previously. Each subject was remotely monitored from the moment of placement until 3 min after crossing out of the center square with both feet. Latencies to begin distress-calling, ambulating, and attempting to escape (i.e., jump, fly out) from the open field were timed on stopwatches to the nearest second. Escape attempts and numbers of lines crossed with both feet were recorded on hand counters. At the completion of each test, the number of defecations deposited in the open field was noted and the floor was wiped clean. Chicks were allowed to remain in the open field for a maximum of $\mathbf{4 0} \mathrm{min}$. If a particular behavior had not occurred during that time, $2,400 \mathrm{sec}$ was assigned as the latency score and zero was recorded for a corresponding frequency measure. Because the total amount of time each bird spent in the open field was dependent upon its ambulation latency score, and since defecations may occur independently of ambulation, number of defecations was converted to a rate measure prior to analysis as a means of equating this variable across subjects for time spent in the open field. The formula used was: [number of defecations/(ambulation latency $+180 \mathrm{sec})] \times 60 \mathrm{sec}$.

\section{Results}

The latency data are depicted in Figure 5. Analyses of variance showed significant differences between groups for latencies to first distress call $[F(4,50)$ $=4.50, \mathrm{p}<.005]$, ambulate $[\mathrm{F}(4,50)=3.32, \mathrm{p}<$ $.025]$, and attempt to escape from the open field $[F(4,50)=2.80, p<.05]$. Trend analyses further showed the linear component to be significant for distress call $[F(1,50)=15.22, p<.001]$, ambulation $[F(1,50)=10.82, p<.005]$, and escape laten-

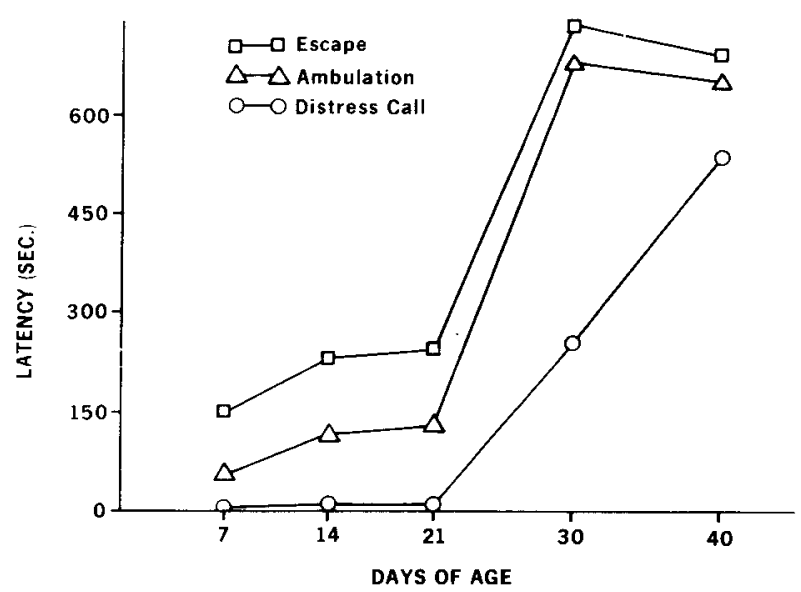

Figure 5. Age-related changes in mean distress-call, ambulation, and escape latencies in chickens.

cies $[F(1,50)=9.19, p<.005]$, with birds showing, on each measure, progressively longer latencies with advancing age. Quadratic, cubic, and quartic trend components were not significant for any latency measures.

Mean number of lines crossed for chicks tested at the different ages were: 7 days $=27.6 ; 14$ days $=17.5 ; 21$ days $=16.8 ; 30$ days $=9.2$; and 40 days $=4.8$. An analysis of variance yielded a significant difference between groups $[F(4,50)=7.34, p<.001]$. The linear trend component was significant $[F(1,50)$ $=27.56, \mathrm{p}<.001]$, with birds crossing fewer lines with increasing age. No other trend components were significant.

Subjects showed the following mean scores for number of escape attempts: 7 days $=1.3 ; 14$ days $=.6 ; 21$ days $=1.2 ; 30$ days $=2.0$; and 40 days $=1.1$. No significant differences between groups was found by an analysis of variance, and a trend analysis showed no components to be statistically significant.

Per-minute defecation rate means for the different groups were: 7 days $=.29 ; 14$ days $=.39 ; 21$ days $=.36 ; 30$ days $=.17$; and 40 days $=.14$. An analysis of variance showed a significant difference between groups $[F(4,50)=4.56, p<.005]$. A trend analysis showed the linear trend component to be significant $[F(1,50)=11.46, p<.005]$. None of the other components were significant.

The results suggest that with advancing maturity in chickens, predator evasion rather than reinstatement behaviors are, in general, more likely to be observed in the open field.

\section{DISCUSSION}

These experiments were conducted to test implications of a model of open-field behavior that has been proposed as an alternative to the general emo- 
tionality hypothesis (Gallup \& Suarez, 1980). This model postulates that the typical open-field testing situation subjects animals to both a simulated predatory encounter with a human being during the handling involved in removal from the home cage and placement in the open field and sudden social separation as a result of being tested in isolation. Behavior in an open field, therefore, can be viewed as a compromise between the opposing tendencies of attempting to avoid further predatory activity and reinstating social contact. Thus, manipulations designed to accentuate predatory elements should lead to a suppression of social reinstatement behaviors (i.e., distress calls, locomotion, escape) and an enhancement of behaviors that would minimize predatory attack (i.e., freezing, silence), and vice versa.

The experiments reported here were designed to further elucidate the role of social reinstatement motivation in open-field behavior in chickens. Experiment 1 used a runway to verify that chicks separated from companions are motivated to reunite. Subjects were found to refrain from approaching when there were no chicks present. In addition, subjects ran faster when there were four birds in the holding compartment at the finish line than when only a single bird was present. Together with the findings of Gaioni and his co-workers (1977), which showed that distress-calling in ducklings was a monotonic function of the number of birds that had been removed from a social group, the present results provide further evidence in support of the notion that separation from a familiar social group motivates an animal to perform behaviors aimed at reestablishing social contact.

The second experiment was conducted to assess the possibility that performance of chicks in a runway is merely a reflection of motivation to investigate any object at the other end. It was found that chicks traversed the runway an average of over four times faster if the holding compartment contained another chick rather than a guinea pig. This supports our assertion that species-specific social reinstatement tendencies are a major factor in motivating movement in a novel enclosure.

In Experiment 3, chicks were housed in groups of 10,6 , or 2 and tested in the open field in pairs. As predicted, there was a significant linear effect on distress-call latency, with birds showing progressively shorter latencies, the larger the number of conspecifics they were separated from during testing. In other words, subjects that were both housed and tested in pairs, and therefore did not experience any social separation, evidenced the least amount of social reinstatement motivation as indexed by distress calling. Birds that were subjected to progressively larger increments of social separation showed a corresponding increase in the like- lihood of emitting distress calls. However, no reliable effects were produced on ambulation latency, indicating that distress calls may be more sensitive to whether the testing condition entails complete or partial social reinstatement. One possible account of this is the proposed dual function of distress calls (Gallup \& Suarez, 1980). Since, for a predator, sounds are harder than movement to localize in space, distress calls may function not only as a contact call, but also as a means of testing the environment for predatory cues prior to the initiation of movement. Thus, the cost/benefit ratio for emitting a distress call in an attempt to reunite with conspecifics may be less than that for ambulation.

Chicks in Experiment 4 were housed in pairs for 10 days and then tested, in the open field, alone, with the cagemate, or with an unfamiliar but comparably aged conspecific. Subjects that were tested individually had shorter latencies to begin distresscalling and ambulating than either of the two pairtested groups. However, contrary to the prediction that subjects that had lived together and presumably formed an attachment bond would show less social reinstatement motivation when they were tested together than when they were tested with strangers, the cagemate and unfamiliar pairs did not differ from each other on distress-call latency. This result is similar to that of Gaioni et al. (1977), who reported that although reducing the size of a group of ducklings produced distress-calling in the remainder of the group, interchanging birds between groups did not (see also Shapiro, 1980). Although the stranger and cagemate groups were also not significantly different on ambulation latency, a significantly greater proportion of subjects in the cagemate group did reach the imposed ceiling.

The fifth experiment examined open-field behavior from a developmental perspective. Groupreared chicks were tested individually at $7,14,21$, 30 , or $\mathbf{4 0}$ days of age. In accord with the prediction that reliance on the social group for such things as nutrition, warmth, and predator defense should decrease with advancing maturity as birds become better able to fend for themselves, distress-call, ambulation, and escape-attempt latencies increased with age. Chicks also showed a decrease in number of lines crossed, the older they were at testing.

These results parallel the developmental study by Candland, Nagy, and Conklyn (1963), who found that distress calls in chicks during a 3-min openfield test were prevalent between 1 and 15 days of age and thereafter, until the final testing age of 90 days, never surpassed $20 \%$ of the number made during the test period. They also found that the percentage of time spent freezing increased from $20 \%$ at 8 days to $50 \%$ between 15 and 45 days of age. An examination of Figure 5 shows that, in the pres- 
ent study, distress-call latency increased by a factor of about 23 and ambulation by a factor of 5 between the ages of 21 and 30 days. It may be that one of the prime motivators for group affiliation in young precocial birds is warmth, and, since it is during this period that chicks acquire a more adultlike plumage, this could account for the exhibited abrupt reduction in social reinstatement behavior. It is widely acknowledged that the thermoregulatory ability of birds depends on their insulation (e.g., Sturkie, 1965), and in light of the behavioral changes we found it may be more than merely coincidental that body temperature in chicks increases with age and asymptotes between 20 to 30 days posthatch (Randall, 1943).

It is also curious to note that the tendency to defecate in the open field decreased with age. We have argued elsewhere that heightened fear in an open field should actually inhibit defecation in both avians and rodents because of the effect odor cues might have on detectability by predators (for evidence in support of this prediction, see Suarez \& Gallup, $1981 a, 1981 b)$. In the present study, the fact that predator evasion tactics became more prominent with age while defecation rate decreased lends further support to this proposition.

The results of Experiment 5 thus suggest that social reinstatement tendencies diminish with age, and that antipredator strategies become more pronounced as animals become less dependent on resources provided by conspecifics. Naturalistic studies by Collias (1952) showing that the young of many precocial avian species tend to aggregate less and distress-call less frequently upon separation as they become older lend support to this contention. We have also found a similar reduction in distress-calling and ambulating with advancing age in guinea pigs (Suarez \& Gallup, 1962b). The most dramatic increases in latency to occurrence for these behaviors occurred between 4 and 5 weeks of age, which coincides with the time at which guinea pig mothers wean their offspring (Pettijohn, 1978; Rood, 1972).

In conclusion, the present series of studies lend support to the notion that motivation to reestablish contact with separated conspecifics is an important factor in open-field behavior in chickens.

\section{REFERENCES}

ADER, R. Effects of early experience and differential housing on behavior and susceptibility to gastric erosions in the rat. Journal of Comparative and Physiological Psychology, 1965, 60, 233-238.

Andrew, R. J. Fear responses in Emberiza Spp. Animal Behaviour, 1956, 4, 125-132.

Archer, J. Tests for emotionality in rats and mice: A review. Animal Behaviour, 1973, 21, 205-235.
Armstrong, E. A. The wren. London: Collins, 1955.

Askew, H. R., Musimeci, M., Slonene, L., \& Stephan, L. Effects of prey movement and background on predatory behavior of chameleons. Psychonomic Science, 1970, 20, 171.

BAron, A., \& Kish, G. B. Early social isolation as a determinant of aggregative behavior in the domestic chicken. Journal of Comparative and Physiological Psychology, 1960, 53, $459-463$.

Berg, R. A., Shanin, R. D., \& Hull, E. M. Early isolation in the gerbil (Meriones unguiculatus): Behavioral and physiological ef fects. Physiology \& Behavior, 1975, 3, 35-38.

Brückner, G. H. Untersuchungen zur Tiersoziologie inbesondere der Auflösung der Familie. Zeitschrift für Psychologie, 1933, 128, 1-120.

Busnel, R. G. Aspects of animal acoustic signals. In R. G. Busnel (Ed.), Acoustic behavior of animals. New York: Elsevier, 1963.

Candland, D. K., Nagy, Z. M., \& Conklyn, D. H. Emotional behavior in the domestic chicken (White Leghorn) as a function of age and developmental environment. Journal of Comparative and Physiological Psychology, 1963, 56, 1069-1073.

Collias, N. E. Social life and the individual among vertebrate animals. Annals of the New York Academy of Sciences, 1950, 51, 1074-1092.

Collias, N. E. The development of social behavior in birds. $A u k, 1952,69,127-159$.

CotT, H. B. Adaptive coloration in animals. New York: Oxford University Press, 1940.

Curio, E. The ethology of predation. New York: Springer, 1976.

Drummond, H. M. Stimulus control of amphibious predation in the northern water snake (Nerodia s. sipedon). Zeitschrift fiir Tierpsychologie, 1979, 50, 18-44.

Gaioni, S. J., Hofrman, H. S., Klein, S. H., \& DePaulo, P. Distress calling as a function of group size in newly hatched ducklings. Journal of Experimental Psychology: Animal Behavior Processes, 1977, 3, 335-342.

Gallup, G. G., JR., \& Sunrez, S. D. An ethological analysis of open-field behaviour in chickens. Animal Behaviour, 1980, 28, 368-378.

GervaIs, M. C. Social and genotypic aspects of open-field behavior in two lines of mice. Behavioral Biology, 1976, 18, 427-431.

Goodrick, C. Social interactions and exploration of young, mature, and senescent male rats. Journal of Gerontology, 1965, 20, $215-218$.

Guhl, A. M., \& Ontman, L. L. Visual patterns in the recognition of individuals among chickens. Condor, 1953, 55, 287-298.

Gurron, P. Socialization and imprinting in Brown Leghorn chicks. Animal Behaviour, 1959, 7, 26-34.

HAll, C. S. Emotional behavior in the rat: Defecation and urination as measures of individual differences in emotionality. Journal of Comparative Psychology, 1934, 18, 385-403.

Herzog, H. A., JR., \& Burahardt, G. M. Prey movement and predatory behavior of juvenile western yellow-bellied racers, Coluber constrictor mormon. Herpetologica, 1974, 30, 285-289.

KAUFMAN, D. W. Differential predation on active and inactive prey by owls. Auk, 1974, 91, 172-173.

KonN, J. H., \& MoYen, K. E. Behavioral effects of isolation in the rat: The role of sex and time of isolation. Journal of Genetic Psychology, 1968, 113, 263-273.

KRUIJT, J. P. Ontogeny of social behaviour in Burmese Red Junglefowl (Gallus gallus spadiceus) Bonnaterre. Behaviour Supplement XII. Leiden: Brill, 1964.

MacDonald, L. Attack latency of Constrictor constrictor as a function of prey activity. Herpetologica, 1973, 29, 45-48.

Petrijohn, T. F. Development of social behavior in young guinea pigs (Cavia porcellus). Journal of General Psychology, 1978, 99, 81-86.

Randall, P. K., \& Campeell, B. A. Ontogeny of behavioral arousal in rats: Effects of maternal and sibling presence. Journal of Comparative and Physiological Psychology, 1976, 90, 453-459. 
Randald, W. C. Factors influencing the temperature regulation of birds. American Journal of Physiology, 1943, 139, 56-67.

Roon, J. P. Ecological and behavioural comparisons of three genera of Argentine cavies. Animal Behaviour Monographs, $1972,5,1-83$.

Shapiro, L. J. Species identification in birds: A review and synthesis. In M. A. Roy (Ed.), Species identity and attachment. New York: Garland Press, 1980.

SuuckIN, W. Imprinting and early learning. Chicago: Aldine, 1965.

STODDARD, H. L. The bobwhite quail: Its habits, preservation and increase. New York: Scribner's, 1936.

Stokes, A. W. Behavior of the bobwhite, Colinus virginianus. Auk, 1967, 84, 1-33.

Sturkie, P. D. Avian physiology (2nd ed.). Ithaca, N.Y: Cornell University Press, 1965.

Suarez, S. D., \& Gallup, G. G., JR. An ethological analysis of open-field behaviour in ducks Anas platyrhynchos. Bird Behaviour, 1980, 2, 93-105.

Suarez, S. D., \& Gallup, G. G., Jr. An ethological analysis of open-field behavior in rats and mice. Learning and Motivation, 1981, 12, 342-363. (a)
Suarez, S. D., \& Gallup, G. G., JR. Predatory overtones of open-field testing in chickens. Animal Learning \& Behavior, 1981, 9, 153-163. (b)

Suarez, S. D., \& Gallup, G. G., JR. Open-field behavior in chickens: The experimenter is a predator. Journal of Comparative and Physiological Psychology, 1982, 96, 432-439. (a)

Suarez, S. D., \& Gallup, G. G., Jr. Open-field behaviour in guinea pigs: Developmental and adaptive considerations. $\mathrm{Be}$ havioral Processes, 1982, 7, 267-274. (b)

Syme, G. J., \& SYMe, L. A. Social inhibition of locomotor activity in mice. Psychological Reports, 1974, 35, 260-262.

Thessen, D. D. Varying sensitivity of C57B1/Crgl mice to grouping. Science, 1963, 141, 827-828.

W Alsh, R. N., \& Cummins, R. A. The open-field test: A critical review. Psychological Bulletin, 1976, 83, 482-504.

White, C. M., \& WEEDEN, R. B. Hunting methods of gyrfalcons and behavior of their prey (ptarmigan). Condor, 1966, 68, 517-519.

(Manuscript received June 14, 1982;

revision accepted for publication September 14, 1982.) 